\title{
SHOULD GOLD BE HELD UNDER GLOBAL ECONOMIC POLICY UNCERTAINTY?
}

\author{
Meng QIN ${ }^{1}$, Chi-Wei SU²*, Yi-Dong XIAO ${ }^{3}$, Shuai ZHANG ${ }^{4}$ \\ ${ }^{1}$ Graduate Academy, Party School of the Central Committee of the Communist \\ Party of China (National Academy of Governance), Beijing, China \\ ${ }^{2}$ School of Economics, Qingdao University, Qingdao, China \\ ${ }^{3}$ Department of Economics, University of California, Berkeley, U.S. \\ ${ }^{4}$ Propaganda Department, Qingdao Central Branch of the People's Bank of China, \\ Qingdao, China
}

Received 28 January 2019; accepted 26 November 2019

\begin{abstract}
This paper investigates the ability of gold to hedge worldwide risks from the perspective of global economic policy uncertainty (GEPU). By applying the full- and sub-sample rolling-window bootstrap causality tests to analyze the dynamic interaction between GEPU and gold price (GP). It can be observed that gold can effectively hedge risks of GEPU during the Asian financial crisis, dot-com bubble and global economic crisis, but this result does not hold in non-crisis period. GEPU manifests two-way impacts on the GP in a few periods, this relationship between GEPU and GP being consistent with the hypothesis in the general equilibrium model, which states that changes in GEPU lead to the fluctuations of GP. In turn, GP has both positive and negative impacts on GEPU. In the current complex economic situation, governments and investors can consider gold to hedge risks of GEPU, especially during the economic crises.
\end{abstract}

Keywords: global economic policy uncertainty, gold price, general equilibrium model, causality, rolling-window, time-varying.

JEL Classification: C32, C51, E66, G12, G18.

\section{Introduction}

The main purpose of this paper is to explore whether gold can effectively hedge risks of GEPU or not. The ability of gold to avoid uncertainty risks is a controversial topic, especially during the economic crises. Jones and Sackley (2016) suggest that the increase in economic policy uncertainty $(\mathrm{EPU})^{1}$ of U.S. and Europe contribute to the growth in GP. Conversely,

\footnotetext{
${ }^{1}$ EPU measures the uncertainty of a country's economic policy (e.g., the U.S.), while GEPU refers to the uncertainty of the global economic policy, which is a GDP-weighted average of EPU for 20 countries.
}

*Corresponding author. E-mail: cwsu7137@gmail.com 
GP is less likely to fall when GEPU has been decreased (Bilgin et al., 2018). However, this opinion is not established in all cases, because it largely depends on the status of the gold market and the level of uncertainty. When the uncertainty attains its highest level and under relatively stable gold market status, gold can be considered as an asset to avoid risks (Jamal et al., 2018). In addition, since the uncertainty has significant impacts on the gold market, the prediction of the volatility of gold futures market, based on GEPU, is reliable and accurate (Fang et al., 2018). In turn, there are several factors that can be taken into account as indicators of uncertainty in economic policy, and among them, GP has been considered as the most significant (Raza et al., 2018). The price of gold can be used as an efficient tool to identify the uncertainty shocks (Piffer \& Podstawski, 2016). The positive gold shocks may increase the probability of being in the high-uncertainty regime (Zhou et al., 2017). In general, there is a mutual influence between GEPU and GP (Balcilar et al., 2016; Raza et al., 2018; Beckmann et al., 2019). According to this mutual influence, it assists the governments to forecast and stabilize the global economy, based on the price of gold, and it also inspires the investors to hedge risks of GEPU, by rationally arranging assets. However, there may be a time-varying causal relationship between GEPU and GP, and the direction of impacts may have differences at different stages, which have not been explored in previous studies. Thus, this paper attempts to address the gaps in the existing studies on these two variables nexus.

As a currency for reserves and investments, gold is considered as a hedge or a safe haven (Beckmann et al., 2015; Bhanja \& Dar, 2015). In times of high GEPU, such as exchange rate fluctuation, economic crises and stock disasters, the investor sentiment will be affected (Lutz, 2015; Ding et al., 2017). Thereby, they tend to invest safer assets which drives GP to increase (Balcilar et al., 2017). The fluctuation of exchange rates, especially the depreciation of the U.S. dollar (because the international GP is denominated in dollars), means that the purchasing power of a country's currency is weakened and investors are more inclined to invest gold (Mills, 2004; Arxiv, 2014; Fan et al., 2014). When the U.S. sub-prime mortgage bubble has burst in 2007, followed by the global economic and European debt sovereign crisis, both the GEPU and GP were at a high level. For instance, in order to recover the economy from the global economic and European sovereign debt crises, a large amounts of bailout policies (e.g., quantitative easing policy in U.S., a four trillion Renminbi stimulus package in China, unconventional monetary policies in U.K.) cause a rise in GEPU, and GP hits the highest level in 2011. Furthermore, GP will rise during the economic crises, so it can be used as a stable asset to avoid risks (Jun, 2009; Bialkowski et al., 2015; Junttila et al., 2018; Beckmann et al., 2019). For this reason, GP is often considered as a surrogate measure of financial instability or crisis (Stockhammer \& Grafl, 2010). By analyzing the Association of Southeast Asian Nations (ASEAN) countries, China, Japan and South Korea, Ziaei (2012) ascertains that any negative changes in the stock market will have a positive impact on the price of gold. Other studies could be found for the U.S. (Gokmenoglu \& Fazlollahi, 2015), India (Jain \& Biswal, 2016), the countries of Brazil, Russia, India, China and South Africa (BRICS), etc., with similar conclusions (Chkili, 2016; Wang, 2019). However, the general view that gold is a hedge or a safe haven is not always recognized. Some existing studies suggest that the ability of gold to hedge risks varies with time and region (Baur \& Mcdermott, 2010; Joy, 2011; Reboredo, 2013). Although it is unclear whether gold can hedge risks of GEPU, it can be observed that 
GP is affected by the world, rather than one country (Christophe \& Julian, 2005). Since gold is considered to have effective hedging ability, each country uses it as one of the main sources of foreign exchange reserves to avoid risks (Aizenman \& Inoue, 2013; Ghosh, 2016). The top three countries, in terms of gold-foreign exchange reserves ratio, are the U.S. (73.4\%), Germany $(68.8 \%)$ and Italy $(65.1 \%)^{2}$, all of them account for a considerable share, which has a special role in stabilizing economy, improving international credit (Bernstein, 1961) and suppressing inflation (Shahzad et al., 2019). The valuation of gold affects the effective level of world reserves (Brodsky \& Sampson, 1980), so the fluctuations of GP also influence the global economic situation, rather than one country (Akaev et al., 2011). Therefore, this paper conducts analysis on the causal relationship between the two variables from global level and focuses on answering whether gold can effectively hedge risks of GEPU.

There are several marginal contributions of this paper. To begin with, the previous studies mainly investigate the causal relationship between GP and EPU of one country. It is widely believed that gold can be considered as a global hedge or a safe haven asset (Piffer \& Podstawski, 2016), so the price of gold is affected by GEPU. This paper is a pioneering effort to probe the causal relationships between GEPU and GP. The empirical results support the general equilibrium model that indicates GEPU has certain impacts on gold market. Moreover, the previous studies exclusively apply the full-sample causality estimation, which ignores the structural changes in time series. In order to ensure the robustness and accuracy of the results, this paper employs the bootstrap sub-sample rolling-window causality test in order to identify the time-varying interaction between GEPU and GP. With this approach, this paper can provide implications for national governments (e.g., rationalize the proportion of gold reserves and judge the economic situation based on the price of gold) and supports investors to avoid the risks of GEPU (e.g., gold is a hedge asset for the real economy, investing gold during an economic crisis can withstand the risks of GEPU).

The structure of the rest of this paper is organized as follows: Section 1 presents the relevant literature of this paper. Section 2 introduces the theoretical model of GEPU and GP. Section 3 reveals the test models of causality. Section 4 describes the data. Section 5 analyzes the results of the empirical analysis. The last section summarizes the study of this paper.

\section{Literature review}

Whether gold can effectively hedge risks of GEPU, it has been the focus of attention over the past decades. As one of the monetary policy tools, the expected rise in interest rates will lead to a negative adjustment in GP (Neill, 1987). Thorarinsson and Eshraghi (2013) state that the unexpected factors of the Federal Reserve System (Fed)'s monetary policy have a major impact on the gold market (also Mixon, 2006; Batten et al., 2010). Yi and Refalo (2013) suggest that the policy of quantitative easing (QE) will lead to market expectations of inflation, which in turn will drive up the price of gold. Kumar (2014) points out that during the economic crisis, gold can be used as a hedging instrument (also Bredin et al., 2015; Ischuk et al., 2016), and the stock-gold portfolio provides better diversification benefits than the

\footnotetext{
$\overline{2}$ The gold-foreign exchange reserves ratio is taken from the World Gold Council (2020).
} 
stock portfolio. Jones and Sackley (2016) reveal that in addition to avoiding inflation, gold is also a hedge for the uncertainty of economic policy, a $1 \%$ increase in EPU of U.S. will cause gold price to rise by $2 \%$ to $3 \%$. Bilgin et al. (2018) present that the deterioration of GEPU will raise the price of gold and the improvement of it is less likely to make the price of gold fall. Fang et al. (2018) prove that GEPU can significantly improve the forecast accuracy of GP, which means GEPU is an indicative indicator of GP. Wu, Tong, Yang, and Derbali (2019) suggest that gold can be used as the weak hedge and safe-haven against EPU in most cases.

However, several studies have argued that GEPU has no significant impact on GP and the ability of gold to hedge risks is uncertain. Price stability is one of the goals of monetary policy, but unexpected changes in inflation will not affect the spot price of gold (Blose, 2010). Wang (2013) finds that in the short term, the excessive depreciation of the U.S. dollar and the overshoot of exchange rate adjustment make gold unable to hedge risks. In 2014, the World Gold Council study concludes that 58\% of gold demand comes from consumption, so GP will not be affected by higher interest rates. Several studies explain these two opposing statements. Baur and Mcdermott (2010) highlights that the hedging ability of gold varies from country to country. Gold is both a hedge and a safe haven for European and the U.S., but not for Australia, Canada, Japan and large emerging markets. Iqbal (2017) divides the gold market into bull and bear situation and finds that, at different statuses of gold market, there are different roles of gold in the hedging or safe harbor of exchange rates, stock markets and inflation. Jamal et al. (2018) also prove that the reaction of gold to EPU of the U.S. depends on the current market and financial environment, so gold cannot efficiently hedge risks at all times.

Even there is an interaction between GEPU and GP, previous studies have selected only a country's EPU and GP to test the causal relationship between the two variables. Balcilar et al. (2016) benefit from nonparametric causality-in-quantiles test results with daily, monthly and quarterly frequencies of data to investigate the causality between the two variables and notice that uncertainty has causal effects on gold returns and volatility. Raza et al. (2018) use the same method to prove that the EPU of eight countries are the reason for the fluctuations of GP. Bahloul, Balcilar, Cunado, and Gupta (2018) find that EPU of U.S. cannot explain gold futures returns, but it has an indicative effect on volatility. Beckmann et al. (2019) employ a copula wavelet approach to evidence that EPU is positively correlated with GP. Consequently, the previous studies have not clarify the interaction mechanism between GEPU and GP. In addition, those studies ignore the time-varying causal relationship between these two variables and fail to identify the direction of the influence. This paper performs the bootstrap sub-sample rolling-window causality test to analyze if gold has the ability to effectively hedge risks and to find what important roles its price plays in decreasing GEPU.

\section{General equilibrium model of GEPU and GP}

Pastor and Veronesi (2012) construct a general equilibrium model to analyze the relationship between the uncertain policy and asset price. GEPU and GP are employed as representative variables, respectively. First, suppose an economy with a continuum of gold investors $i$ $(i \in[0,1])$ and a finite horizon $[0, T]$. Second, suppose all investors' capital is equivalent in time $0\left(C_{0}^{i}=1\right)$. From time 0 , investors continue to invest all their capital linearly, and the 
return on investment in gold $\left(\mathrm{GP}_{t}^{i}\right)$ is random. The investor's capital accumulation equation is $d C_{t}^{i}=C_{t}^{i} d \mathrm{GP}_{t}^{i}$, where $C_{t}^{i}$ means the capital stock of investor $i$ at time $t$. Then a regression equation is set up for the whole time interval $t \in[0, T]$ as follow:

$$
d \mathrm{GP}_{t}^{i}=\left(u+g_{t}\right) d t+\sigma d Z_{t}+\sigma_{1} d Z_{t}^{i} .
$$

In Eq. (1), $u$ is an observable constant indicates other factors which have impacts on the gold market. $\sigma$ and $\sigma_{1}$ are the corresponding coefficients that can be observed. $Z_{t}$ is a Brownian motion, and $Z_{t}^{i}$ is an independent Brownian motion specifically for investors $i$. $g_{t}$ denotes that economic policy has effects on the average of the profitability process of each investor. There is no relationship between economic policy and GP if $g_{t}=0$.

$g^{\text {old }}$ denotes the current government policy's impact, which will remain unless this policy is adjusted at time $\tau(0<\tau<T)$. The government decides whether to change the economic policy, at this time. If government changes the current economic policy, the impact replaces $g^{\text {old }}$ by $g^{\text {new }}$. The value of $g_{t}$ can be written as follow:

$$
g_{t}=\left\{\begin{array}{l}
g^{\text {old }} \text { for } t \leq \tau ; \\
g^{\text {old }} \text { for } t>\tau, \text { if there is no policy change } \\
g^{\text {new }} \text { for } t>\tau, \text { if there is a policy change. }
\end{array}\right.
$$

In Eq. (2), after government announcing the implementation of new policy at time $\tau$, it becomes effective immediately, but none of the participants - government as well as investors who invest gold know the value of $g_{t}$ where $t \in[0, T]$. An important presumption is that government policies have uncertain effects on the benefits of investors. At time 0 , both $g^{\text {old }}$ and $g^{\text {new }}$ have normal prior distributions with mean zero and known variance $\sigma_{g}^{2}$, that is $g \sim N\left(0, \sigma_{g}^{2}\right)$.

Due to the complexity and variability of the global economy, the formulation and implementation of economic policies must have a certain degree of elasticity. Once the situation changes, such as economic crises, the economic policy must be adjusted accordingly (Taylor, 2009). Then, this adjustment will inevitably lead to the uncertainty of global economic policy (expressed by $\sigma_{g}$, the standard deviation of $g_{t}$ ). If consider an economic crisis, the uncertainty $\left(\sigma_{g}\right)$ will increase, which means the fluctuations in the time series $\left(g_{t}\right)$ are greater. It can be noticed that there is a big difference between $g^{\text {old }}$ and $g^{\text {new }}$, but cannot assess the size of them. If $g^{\text {new }}>g^{\text {old }}$, GEPU will have a positive impact on GP, this means that the price of gold will maintain at a high level during the economic crisis, hence gold can efficiently hedge risks of uncertainty, and vice versa. Therefore, from this general equilibrium model, it can be concluded that the changes of GEPU lead to the fluctuations of GP, but the direction of influence remain uncertain.

\section{Methodology}

\subsection{Bootstrap full-sample causality test}

In the Granger causality test, based on the traditional vector autoregression (VAR) model, the test statistics may not comply the standard asymptotic distributions. This may cause dis- 
tortion of the test results. In order to overcome this problem, Shukur and Mantalos (1997) propose the residual-based bootstrap $(R B)$ method's critical values and they prove that this method can improve the causality test. Moreover, they also find that the $R B$ method is relatively better for standard asymptotic tests and in small sample, the characteristics of power and size can revise the likelihood ratio (LR) tests (Shukur \& Mantalos, 2000). Therefore, in this paper, the $R B$-based modified- $L R$ statistic is used to test the causal relationship between GEPU and GP.

The VAR $(p)$ process is constructed by two variables as follows:

$$
X_{t}=\beta_{0}+\beta_{1} X_{t-1}+\ldots+\beta_{p} X_{t-p}+\varepsilon_{t}, t=1,2, \ldots \ldots, T,
$$

where the optimal lag order $p$ is determined by the Schwarz Information Criterion (SIC). The VAR $(p)$ process by splitting $X$ into GEPU and GP, $X_{t}=\left(\mathrm{GEPU}_{t}, \mathrm{GP}_{t}\right)^{\prime}$. Eq. (3) can be rewritten as follow:

$$
\left[\begin{array}{l}
\mathrm{GEPU}_{t} \\
\mathrm{GP}_{t}
\end{array}\right]=\left[\begin{array}{l}
\beta_{10} \\
\beta_{20}
\end{array}\right]+\left[\begin{array}{ll}
\beta_{11}(L) & \beta_{12}(L) \\
\beta_{21}(L) & \beta_{22}(L)
\end{array}\right]\left[\begin{array}{l}
\mathrm{GEPU}_{t} \\
\mathrm{GP}_{t}
\end{array}\right]+\left[\begin{array}{l}
\varepsilon_{1 t} \\
\varepsilon_{2 t}
\end{array}\right],
$$

where $\varepsilon_{t}=\left(\varepsilon_{1 t}, \varepsilon_{2 t}\right)^{\prime}$ is a white-noise process with zero mean and covariance matrix. $\beta_{i j}(L)=\sum_{k=1}^{p} \beta_{i j, k} L^{k}, i, j=1,2$ and $L$ is the lag operator, defined as $L^{k} X_{t}=X_{t-k}$.

Then, according to the Eq. (4), it can be examined the null hypothesis that $\beta_{12, k}=0$ for $k=1,2, \ldots, p$, which means that the changes of GP have no effects on GEPU. This null hypothesis will be rejected if GP is a significant cause of GEPU, and vice versa. The inverse null hypothesis that the changes of GEPU have no effects on GP will be rejected in the similar way.

\subsection{Parameter stability test}

In the bootstrap full-sample causality test, it is assumed that there is no structural change in the parameters. However, in practice, this assumption is often not satisfied, therefore it is unreasonable to perform the full-sample causality test. Thus, by using the Sup-F, Ave-F and Exp-F tests, developed by Andrews (1993) and Andrews and Ploberger (1994), to test the robustness of the parameters. Sup- $F$ can test for a sudden structural change, Ave- $F$ and Exp-F can test whether the parameters have a gradually evolve along the time trajectory or not. If there is a structural change in the parameters, it should be considered the bootstrap sub-sample rolling-window test to analyze the causality between the two variables.

\subsection{Bootstrap sub-sample rolling-window causality test}

The test developed by Balcilar, Ozdemir, and Arslanturk (2010) involves dividing the whole time series into small samples, according to the rolling-window width for causality test. The divided small samples are gradually scrolled from the beginning to the end of the whole sample. The detailed steps are as follows: Assume that the length of time series is $T$ and the sample length is $l$. The end of each sub-sample is $l, l+1, \ldots, T$ and $T-l+1$ sub-samples can be 
obtained. Each sub-sample can achieve a causality test result by using the $R B$-based modified$L R$ test. By summarizing all the observed probability values $p$ and $L R$ statistics in chronological order, it can be obtained the results of the causality test of the sub-sample rolling-window. The average of a large number of estimation $N_{b}^{-1} \sum_{k=1}^{p} \hat{\beta}_{12, k}^{*}$ and $N_{b}^{-1} \sum_{k=1}^{p} \hat{\beta}_{21, k}^{*}$ represent GP's impact on GEPU and GEPU's impact on GP respectively, where $N_{b}$ represents the times of bootstrap repetitions, $\hat{\beta}_{12, k}^{*}$ and $\hat{\beta}_{21, k}^{*}$ are estimates from the VAR models. This paper uses a $90 \%$ confidence interval, with the corresponding lower and upper bounds being the 5 th and 95th quantiles of $\hat{\beta}_{12, k}^{*}$ and $\hat{\beta}_{21, k}^{*}$, respectively (Balcilar et al., 2010; Su et al., 2019a, 2019b).

\section{Data}

This paper considers monthly data from 1997:M1 to 2018:M11 to examine the hedging ability of gold. During these 12 years, there have been a large number of economic crises in the world (e.g., 1997 Asian financial crisis, 2007 sub-prime crisis, 2009 European sovereign debt crisis). For instance, the gross world product (GWP) has declined $0.34 \%$ in 1997, during the Asian financial crisis. After the U.S. sub-prime mortgage crisis, the growth rate of GWP in 2009 was $-5.19 \%$. Economic crises may increase the uncertainty of economic policy. Baker, Bloom, and Davis (2016) develop EPU index, which measures the uncertainty of a country's economic policy. EPU index reflects the relative frequency of a country's newspapers that include three types of underlying terms: economy (E), policy (P) and uncertainty (U). The higher EPU means the degree of uncertainty of economic policy is high, and vice versa. Since the gold market is affected by global crises or fluctuations (Fang et al., 2018), this paper considers GEPU ${ }^{3}$ (Davis, 2016), which is a GDP-weighted average of EPU for 20 countries $^{4}$, in order to measure the uncertainty of the global economic policy. To eliminate the potential heteroscedasticity of GEPU, by using natural logarithms. The issue on if gold can effectively hedge risks of GEPU, this paper uses the spot price of gold to analyze the impact of GEPU to gold market. Due to GEPU reflects the global situation and the international gold price is denominated in U.S. dollars, this paper also employs the price of gold in this unit of pricing ${ }^{5}$ (GP) for our analysis. In this paper, GP is transformed by taking natural logarithms and first differences to avoid the potential heteroscedasticity and non-stationary. From the outbreak of the sub-prime mortgage crisis to the European sovereign debt crisis, GP has raised over 150\% in 2013 from 2007. During this period, the GEPU is at a relatively high level, accompanied by a rise in the price of gold.

Table 1 illustrates the descriptive statistics. The means of GEPU and GP denote that their series are concentrated at the 112.062 and 825.741 levels, respectively. The skewness is positive both in terms of GEPU and GP. The kurtosis of GEPU demonstrates the feature of a fat tail. Moreover, the Jarque-Bera test proves that GEPU and GP are significantly non-normally distributed at $1 \%$ level. Therefore, it is not appropriate to perform the traditional method for Granger causality test. In order to ensure the reliability of the analysis results, this paper

\footnotetext{
$\overline{3}$ The EPU and GEPU index is taken from http://www.policyuncertainty.com/index.html.

${ }^{4}$ The 20 countries are Australia, Brazil, Canada, Chile, China, France, Germany, Greece, India, Ireland, Italy, Japan, Mexico, the Netherlands, Russia, South Korea, Spain, Sweden, the U.K. and the U.S.

5 The price of gold in U.S. dollars is taken from the World Gold Council (https://www.gold.org/).
} 
applies the bootstrap sub-sample rolling-window causality test to analyze the interaction between the two variables.

Table 1. Descriptive statistics for GEPU and GP

\begin{tabular}{|l|c|c|}
\hline & GEPU & GP \\
\hline Mean & 112.062 & 825.741 \\
\hline Median & 101.418 & 803.200 \\
\hline Maximum & 283.092 & 1771.900 \\
\hline Minimum & 50.393 & 256.100 \\
\hline Standard Deviation & 45.473 & 479.559 \\
\hline Skewness & 1.169 & 0.253 \\
\hline Kurtosis & 4.365 & 1.604 \\
\hline Jarque-Bera & $80.002^{* * *}$ & $24.157^{* * *}$ \\
\hline
\end{tabular}

Note: ${ }^{* *}$ denotes significance at the $1 \%$ level.

\section{Empirical results}

According to the Eq. (4), bivariate VAR models are constructed with GEPU and GP to estimate the full-sample causal relationship. The optimal lag order selected based on SIC is 1 . Table 2 reports the full-sample causality test results based on the $R B$-based modified- $L R$ causality tests. The results highlight that the relationship between the $p$-value of GEPU and GP is not obvious, which means that GEPU does not Granger cause GP and vice versa. The results are in conflict with previous studies (Balcilar et al., 2016; Raza et al., 2018; Beckmann et al., 2019) and also with the hypothesis of theoretical model, which states that GP is affected by GEPU.

Table 2. Full-sample Granger causality tests

\begin{tabular}{|c|c|c|c|c|}
\hline \multirow{2}{*}{ Tests } & \multicolumn{2}{|c|}{$\mathrm{H}_{0}$ : GEPU does not Granger cause GP } & \multicolumn{2}{l|}{$\mathrm{H}_{0}$ : GP does not Granger cause GEPU } \\
\cline { 2 - 5 } & Statistics & $p$-values & Statistics & $p$-values \\
\hline Bootstrap $L R$ test & 0.738 & 0.400 & 2.699 & 0.101 \\
\hline
\end{tabular}

Notes: To calculate $p$-values using 10,000 bootstrap repetitions.

The bivariate VAR models are used a full sample in estimations, the parameters are fixed values, and the whole sample period has only one causal relationship. However, the parameters may not be constant, due to the structural changes. The casual relationship between GEPU and GP may reveal time-variations (Balcilar \& Ozdemir, 2013). In order to ensure the reliability of the causality test, this paper investigates the temporal stability of parameters in the VAR models with GEPU and GP by using the Sup-F, Ave-F and Exp-F tests. To test for all parameters in the overall VAR system, this paper also applies the $L_{c}$ statistics test, developed by Nyblom (1989) and Hansen (1992). The parameter stability test results are reported in Table 3. 
Table 3. The results of parameter stability test

\begin{tabular}{|l|c|c|c|c|c|c|}
\hline \multirow{2}{*}{ Tests } & \multicolumn{2}{|c|}{ GEPU } & \multicolumn{2}{c|}{ GP } & \multicolumn{2}{c|}{ VAR system } \\
\cline { 2 - 7 } & Statistics & $p$-value & Statistics & $p$-value & Statistics & $p$-value \\
\hline Sup-F & $18.390^{* *}$ & 0.046 & $19.857^{* *}$ & 0.027 & $25.000^{*}$ & 0.089 \\
\hline Ave-F & $10.583^{* *}$ & 0.018 & 6.544 & 0.201 & $14.327^{*}$ & 0.085 \\
\hline Exp-F & $6.314^{* *}$ & 0.040 & $6.487^{* *}$ & 0.035 & 8.572 & 0.139 \\
\hline$L_{c}$ & & & & & $2.429^{*}$ & 0.069 \\
\hline
\end{tabular}

Notes: To calculate $p$-values using 10,000 bootstrap repetitions.

${ }^{* *}$ and ${ }^{*}$ denote significance at the $5 \%$ and $10 \%$ levels, respectively.

From Table 3, the Sup-F tests highlight that there is a sudden structural change in the GEPU and GP at the 5\% level and the VAR models at the $10 \%$ level. The Ave-F and Exp-F tests suggest that parameters may gradually evolve along the time trajectory in the GEPU at 5\% level. The Exp-F test is significant in the GP at 5\% level but not in the VAR models. The Ave-F test is significant in the VAR models at $10 \%$ level but not in the GP. And the $L_{c}$ statistics test against the null hypothesis that parameters of the VAR models follow a random walk process at the $10 \%$ level, which indicates non-constant parameter in the overall VAR models. In general, the stability tests point out that the parameters are significantly unstable in our analysis. Therefore, the results of the full-sample causality test are not accurate. Then, it is introduced the bootstrap sub-sample rolling-window causality test to analyze the timevarying causal relationship between GEPU and GP.

The $R B$-based modified- $L R$ causality method is used in the bootstrap sub-sample rolling-window causality test between GEPU and GP. This paper applies the VAR models in Eq. (4) in order to estimate the bootstrap $p$-values and $L R$-statistics. The null hypothesis is considered that GEPU does not Granger cause GP and vice versa. For the selection of the rolling-window width, a large one can improve the prediction accuracy, but the number of scrolls is reduced. A small one is difficult to ensure the reliability of the results. Pesaran and Timmermann (2005) suggest that, if there is a structural change, the rolling-window width should not be less than 20 . Thus, this paper selects 24 months $^{6}$ to ensure the accuracy of our causality analysis. In addition, it is also investigated the direction of the influence of GEPU on GP (or the influence of GP on GEPU).

Figure 1 and 2 highlight the bootstrap probability value and the direction of the influence of GEPU on GP, respectively. The null hypothesis that GEPU does not Granger cause GP can be accepted, except 1999:M6-1999:M8, 2001:M6-2001:M8, 2007:M10-2008:M3, 2010:M62010:M7 and 2018:M8-2018:M9 at the significance level of 10\%. And during these periods, both positive effects (1999:M6-1999:M8, 2001:M6-2001:M8 and 2007:M10-2008:M3) and negative effects (2010:M6-2010:M7 and 2018:M8-2018:M9) exist from GEPU to GP.

First, considering the positive effects. The Asian financial crisis started in 1997 and ended in 1999, during this period, Russia also triggered the Ruble crisis. The International Mon-

\footnotetext{
6 To prove the reliability of the test results, this paper also uses the rolling-window widths of 20-, 28- and 32- months to explore the causality, and the results are consistent with the 24 months rolling-window.
} 
etary Fund (IMF) made some concessions, after insisting initially on contractionary and high-interest-rate policies (Griffithjones et al., 1998). Central banks used unconventional monetary policies, such as the sharp depreciation of Russian Ruble (Fic \& Saqib, 2006), the depreciation of Renminbi, the reform of the financial sector in ASEAN-4 economies (Singapore, Malaysia, Thailand and Vietnam) and South Korea (Goldstein, 2011) and the bank recapitalization of public funding in Thailand (Bayoumi \& Gagnon, 2018). Meanwhile, other policies were implemented, such as fiscal expansion in Japan and avoiding protectionism and

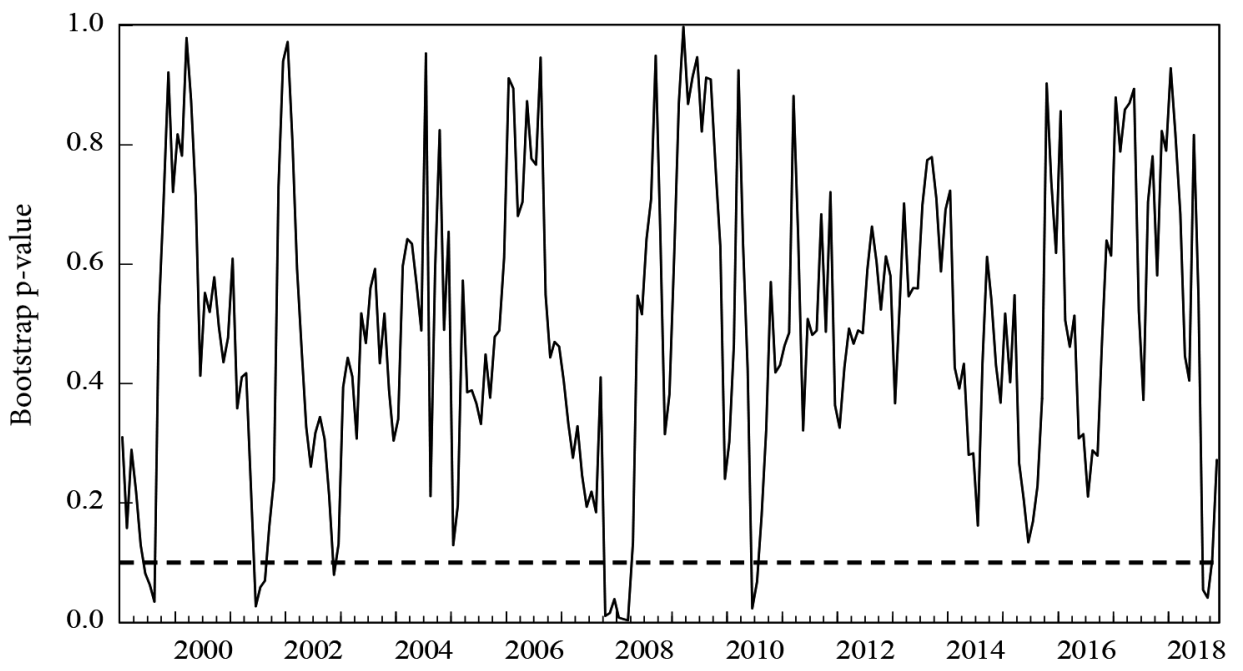

Figure 1. Bootstrap $p$-values of rolling test statistic testing the null hypothesis that GEPU does not Granger cause GP

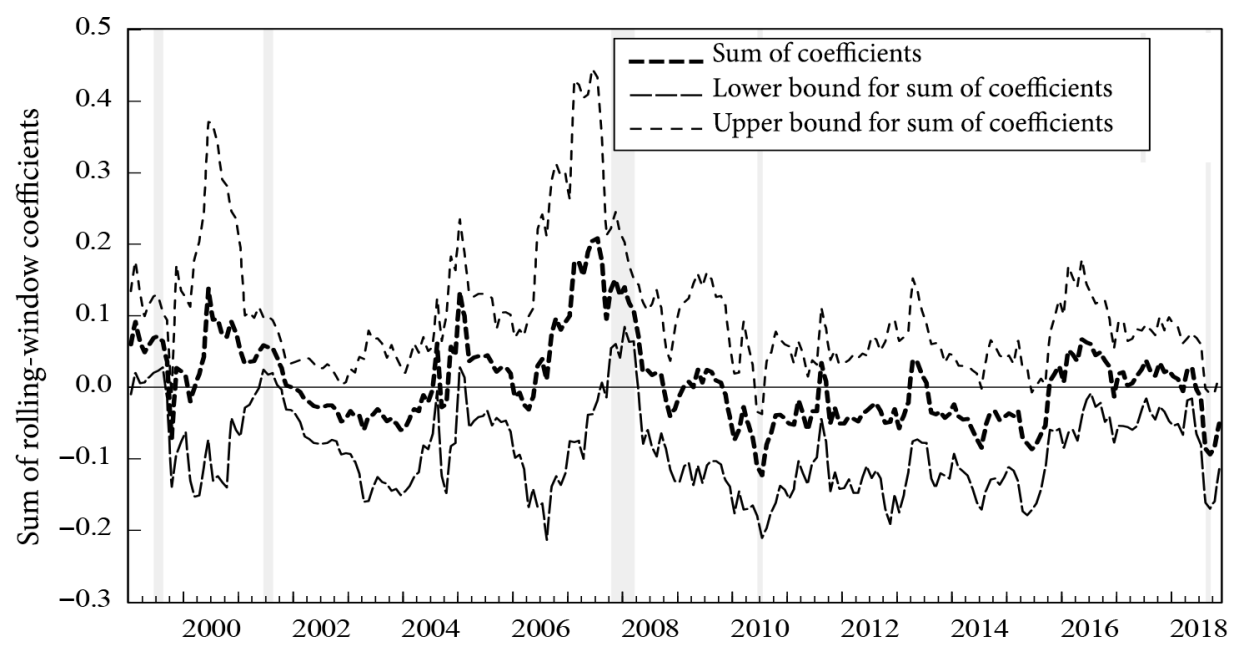

Figure 2. Bootstrap estimates of the sum of the rolling-window coefficients for the impact of GEPU on GP 
maintaining growth in the G7 countries ${ }^{7}$. These changes in government economic policies increase the GEPU in 1999:M6-1999:M8, which makes investors pessimistic and more willing to invest in relatively stable assets, such as gold (Qadan \& Yagil, 2012). The demand for gold will increase, which leads to a significant growth in the price, so GP fluctuates in the same direction due to the positive effects. Furthermore, since the rise of GP, holding gold has a role in maintaining value and can effectively hedge risks of GEPU during the Asian financial crisis and the Ruble crisis.

In the stock markets of Europe, the U.S. and Asia, the share prices of technology and emerging Internet-related companies have risen rapidly from 1995. After reaching its peak on March 10, 2000, the dot-com bubble burst and has significant effects on the economy and this bubble nearly collapsed in 2001. During this period, the U.S. implemented a low-interest monetary policy, which was also the fuse of the U.S. real estate bubble (Lin \& Treichel, 2012). At the same time, countries have begun to adopt stricter Internet governance policies, such as the Sarbanes-Oxley Act in the U.S. (Goodnight \& Green, 2010) and the Decision on Maintaining Internet Security in China. The implementation of these policies has increased GEPU in 2001:M6-2001:M8, and also changed consumer and investor confidence in stock markets (Leger \& Leone, 2008), which has increased the demand for other assets, such as housing and gold. The rise in the price of gold means that it can be used as a hedge under the uncertainty of dot-com bubble.

In 2007, the U.S. financial crisis broke out, and its influence in 2008 jeopardized the global economic market (Longstaff, 2010). In order to get rid of economic difficulties, countries immediately adjusted its tax policies, monetary policies and trade policies, such as a four trillion Renminbi stimulus package in China (Yu, 2008), unconventional monetary policies in U.K. (Hodson \& Mabbett, 2009) and temporary amendments of short-term export credits in the European Commission (Curran et al., 2009). However, there are still erroneous in implemented policies (Taylor, 2009; Su et al., 2017) that further exacerbate the financial crisis (e.g., raise the price of oil). Therefore, enormous changes in global economic policies, especially erroneous policies, have increased GEPU in 2007:M10-2008:M3. In this period of high GEPU, GP has skyrocketed and its currency and hedging characteristics have been well reflected (Jun, 2009). The intervals that GEPU has positive impacts on GP correspond to the above crises respectively, and gold has a relatively high rate of return over other assets. Therefore, gold has an effective function of maintaining value and hedging risks of GEPU during the economic crises.

Then, considering the negative effects. With the global economic crisis gradually fading, the uncertainty of global policy has decreased in 2010:M6-2010:M7. However, the reduction in GEPU will not cause GP to fall immediately (Bilgin et al., 2018). GP is still increasing during this time, thus there is a negative impact from GEPU to it. Issues such as Sino-U.S. trade frictions and high deficit rate in Italian economy have curbed the optimism of the global economy, then GEPU will continue to increase in 2018:M8-2018:M9. This should have increased the gold demand for avoiding risks, but as the Fed raises interest rates in March, June and September 2018 which reduce the willingness of investors to invest gold. Therefore,

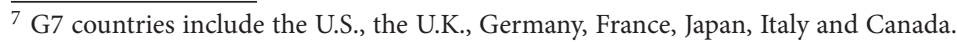


even if the global economic policy is uncertain, the price of gold will fall due to the interest rate hike (Wang \& Chueh, 2013). In general, negative effects can be explained in two ways. First, the decline in GEPU will not lead to an immediate decline in GP. Second, GP is also related to factors such as the Fed's interest rate hike and the appreciation of a country's currency. If other asset returns are more attractive than gold in an environment with high GEPU, the hedging ability of gold will no longer work. Whether the effect is positive or negative, the above analyses are consistent with the general equilibrium model, which states that GEPU has certain impacts on GP.

Figure 3 and 4 evidence the bootstrap probability value and the direction of the influence of GP on GEPU, respectively. The null hypothesis that GP does not Granger cause GEPU can be accepted except 2008:M10-2009:M1, 2009:M10-2009:M11, 2013:M10-2014:M1 and 2017:M10-2017:M11 at the significance level of 10\%. And during this period, both positive effects (2013:M10-2014:M1) and negative (2008:M10-2009:M1, 2009:M10-2009:M11 and 2017:M10-2017:M11) effects exist from GP to GEPU.

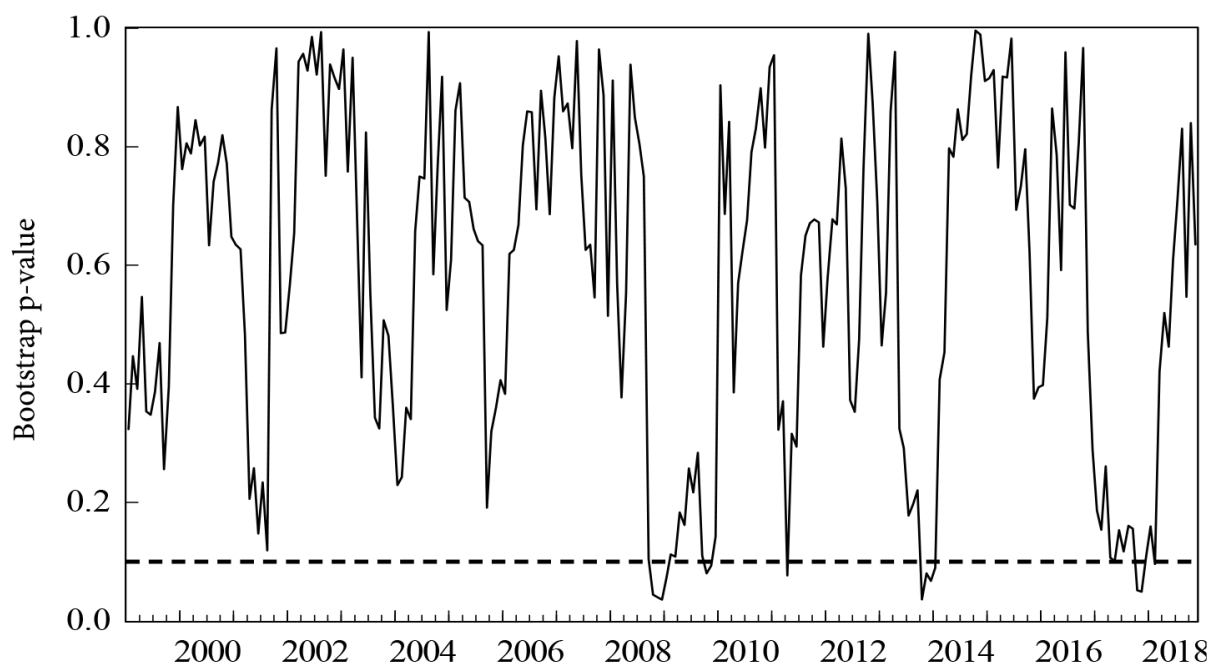

Figure 3. Bootstrap $p$-values of rolling test statistic testing the null hypothesis that GP does not Granger cause GEPU

First, considering the positive effects. Since 2013, the Fed has gradually exited from quantitative easing policy, which means that the U.S. is recovering from the economic crisis (Wen, 2014). The recovery of the U.S. economy will not only determine the dollar appreciation, but also improve the confidence of consumers and investors, and they will be more optimistic about the dollar. Generally, gold and the dollar are negatively related (Pukthuanthong \& Roll, 2011), the appreciation of the dollar reduces the investment demand for gold, which leads to a decline in its price in 2013:M10-2014:M1. At this point, the fall in gold price means that other assets are more profitable, such as dollar. Meanwhile, it also implies that the economic environment is improving and the uncertainty of policy is decreasing. Thus, there is a positive effect from GP to GEPU which depends on the returns of other assets and the global economic situation. 


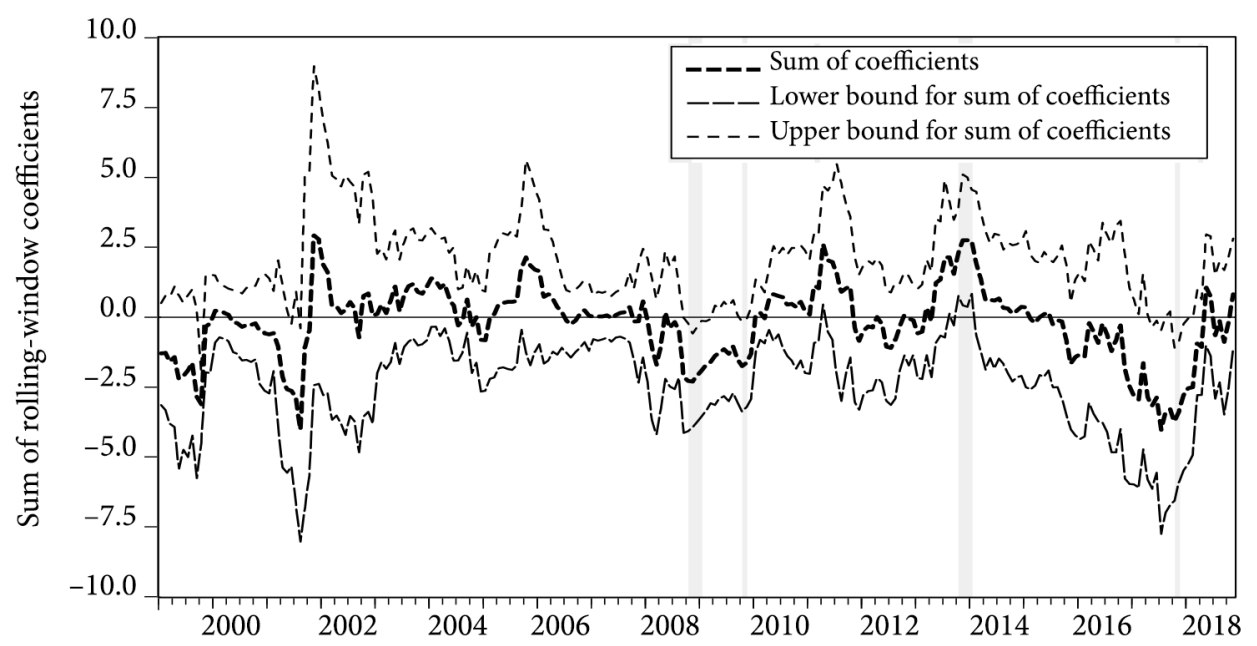

Figure 4. Bootstrap estimates of the sum of the rolling-window coefficients for the impact of GP on GEPU

Then, considering the negative effects. During the global economic crisis, investors invest in gold to hedge risks of GEPU, which raises GP in 2008:M10-2009:M1 and 2009:M102009:M11. In turn, the rise in GP has reduced the risks of governments' foreign exchange reserves and changed the investor confidence (Qadan \& Yagil, 2012), which will stabilize the economy and reduce the uncertainty of economic policy. This can be also explained by the negative impact in 2017:M10-2017:M11. Global economic policies include political unrest and trade wars have increased the uncertainty of global economy during this period. A highly uncertain environment may raise the price of gold, which in turn will help reduce GEPU. Therefore, GP will have negative impacts on GEPU, especially during the financial crises and highly uncertain environment.

To sum up, the causal relationship analysis between GEPU and GP proves that the rollingwindow causality test is effective when parameters are not stable. During the economic crises, GEPU has a significantly positive effect on GP, which can maintain at a high level, when the degree of uncertainty is increasing. Therefore, gold can efficiently hedge risks of GEPU, which is benefit for countries and investors, especially during the global crises. However, in the periods of non-crisis and high GEPU, other assets may be more profitable than gold, the idea that gold is a hedge asset to avoid GEPU is no longer valid at this time. In addition, due to the ratchet effect of gold (Lian \& Zhang, 2013), GP will not fall immediately when GEPU declines. The above results also confirm the hypothesis in the general equilibrium model that GEPU has certain impacts on GP. In turn, GP also has both positive and negative impacts on GEPU by changing investor confidence and investing other assets for higher returns. 


\section{Conclusions}

This paper tests the causality between economic policy uncertainty and gold price in order to explore whether gold can hedge risks of uncertainty and how GP affects GEPU. The fullsample test results does not support the causality between GEPU and GP. Following, this paper turns to account the sub-sample test, which supports the causal relationship between the two variables in few periods. It can be found that gold can effectively hedge risks of GEPU during the Asian financial crisis, dot-com bubble and global economic crisis. However, such a result is not held in the non-crisis and high GEPU periods. Therefore, the ability of gold to hedge risks of GEPU depends on whether or not it is during an economic crisis. In addition, the decrease in GEPU will not lead to an immediate decline in GP. These results are consistent with the hypothesis in the general equilibrium model, which states that the changes in global economic policy cause GEPU, and lead to the fluctuations of GP. In turn, GP has both positive and negative impacts on GEPU, dependent of the investor sentiment, returns of other assets and the global economic situation. In general, the significant interactions of the two variables are mainly accompanied by the occurrence of major global events, such as economic crises. Understanding the hedging ability of gold and the interaction mechanism between the two variables can offer to governments and investors a revelation, which is conducive to avoiding risks of GEPU and promoting healthy development of global economy. Since gold has always been considered to be stored in chaotic era, it is not comprehensive to measure the hedging ability only from the perspective of GEPU. In the future, this study will consider that whether gold can avoid risks of geopolitical risks, such as wars and conflicts, in order to further ascertain its hedging ability.

\section{Disclosure statement}

No potential conflict of interest was reported by the author(s).

\section{References}

Aizenman, J., \& Inoue, K. (2013). Central banks and gold puzzles. Journal of the Japanese \& International Economies, 28(2), 69-90. https://doi.org/10.3386/w17894

Akaev, A. A., Sadovnichii, V. A., \& Korotaev, A. V. (2011). Huge rise in gold and oil prices as a precursor of a global financial and economic crisis. Doklady Mathematics, 83(2), 243-246. https://doi.org/10.1134/s1064562411020372

Andrews, D. W. K. (1993). Tests for parameter instability and structural change with unknown change point. Econometrica, 61(4), 821-856. https://doi.org/10.2307/2951764

Andrews, D. W. K., \& Ploberger, W. (1994). Optimal tests when a nuisance parameter is present only under the alternative. Econometrica, 62(6), 1383-1414. https://doi.org/10.2307/2951753

Arxiv, Q. F. A. (2014). Gold prices and exchange rates: A time-varying copula analysis. Applied Financial Economics, 24(1), 41-50. https://doi.org/10.1080/09603107.2013.859375

Bahloul, W., Balcilar, M., Cunado, J., \& Gupta, R. (2018). The role of economic and financial uncertainties in predicting commodity futures returns and volatility: Evidence from a nonparametric causality-in-quantiles test. Journal of Multinational Financial Management, 45, 52-71. https://doi.org/10.1016/j.mulfin.2018.04.002 
Baker, B., Bloom, N., \& Davis, S. J. (2016). Measuring economic policy uncertainty. The Quarterly Journal of Economics, 131(4), 1593-1636. https://doi.org/10.1163/2210-7975_HRD-9985-2015017

Balcilar, M., Bonato, M., Demirer, R., \& Gupta, R. (2017). The effect of investor sentiment on gold market return dynamics: Evidence from a nonparametric causality-in-quantiles approach. Resources Policy, 51, 77-84. https://doi.org/10.1016/j.resourpol.2016.11.009

Balcilar, M., Gupta, R., \& Pierdzioch, C. (2016). Does uncertainty move the gold price? New evidence from a nonparametric causality-in-quantiles test. Resources Policy, 49, 74-80. https://doi.org/10.1016/j.resourpol.2016.04.004

Balcilar, M., \& Ozdemir, Z. A. (2013). The export-output growth nexus in Japan: A bootstrap rolling window approach. Empirical Economics, 44, 639-660. https://doi.org/10.1007/s00181-012-0562-8

Balcilar, M., Ozdemir, Z. A., \& Arslanturk, Y. (2010). Economic growth and energy consumption causal nexus viewed through a bootstrap rolling window. Energy Economics, 32(6), 1398-1410. https://doi.org/10.10-16/j.eneco.2010.05.015

Batten, J. A., Ciner, C., \& Lucey, B. M. (2010). The macroeconomic determinants of volatility in precious metals markets. Resources Policy, 35(2), 65-71. https://doi.org/10.2139/ssrn.1148741

Baur, D. G., \& Mcdermott, T. K. (2010). Is gold a safe haven? International evidence. Journal of Banking and Finance, 34(8), 1886-1898. https://doi.org/10.2139/ssrn.1516838

Bayoumi, T., \& Gagnon, J. (2018). Unconventional monetary policy in the Asian financial crisis. Pacific Economic Review, 23(1), 80-94. https://doi.org/10.1111/1468-0106.12254

Beckmann, J., Berger, T., \& Czudaj, R. (2015). Does gold act as a hedge or a safe haven for stocks? A smooth transition approach. Economic Modelling, 48(1), 16-24. https://doi.org/10.1016/j.econmod.2014.10.044

Beckmann, J., Berger, T., \& Czudaj, R. (2019). Gold price dynamics and the role of uncertainty. Quantitative Finance, 19(4), 663-681. https://doi.org/10.1080/14697688.2018.1508879

Bernstein, E. M. (1961). The adequacy of United States gold reserve. American Economic Review, 51(2), 439-446. https://www.jstor.org/sta-ble/1914508

Bhanja, N., \& Dar, A. B. (2015). The beauty of gold is, it loves bad news: Evidence from three major gold consumers. Economic Change \& Restructuring, 48(3-4), 187-208. https://doi.org/10.1007/s10644-015-9160-z

Bialkowski, J., Bohl, M. T., Stephan, P., \& Wisniewski, T. P. (2015). The gold price in times of crisis. International Review of Financial Analysis, 41, 329-339. https://doi.org/10.1016/j.irfa.2014.07.001

Bilgin, M. H., Gozgor, G., Lau, C. K. M., \& Sheng, X. (2018). The effects of uncertainty measures on the price of gold. International Review of Financial Analysis, 58, 1-7.

https://doi.org/10.10-16/j.irfa.2018.03.009

Blose, L. E. (2010). Gold prices, cost of carry, and expected inflation. Journal of Economics \& Business, 62(1), 35-47. https://doi.org/10.1016/j.jeconbus.2009.07.001

Bredin, D., Conlon, T., \& Potì, V. (2015). Does gold glitter in the long-run? Gold as a hedge and safe haven across time and investment horizon. International Review of Financial Analysis, 41, 320-328. https://doi.org/10.2139/ssrn.2483728

Brodsky, D. A., \& Sampson, G. P. (1980). The value of gold as a reserve asset. World Development, 8(3), 175-192. https://doi.org/10.1016/0305-750X(80)90008-X

Chkili, W. (2016). Dynamic correlations and hedging effectiveness between gold and stock markets: Evidence for BRICS countries. Research in International Business and Finance, 38, 22-34. https://doi.org/10.1016/j.ribaf.2016.03.005

Christophe, F., \& Julian, V. (2005). The price of gold: A global required yield theory. Journal of Investing, 14(1), 99-111. https://doi.org/10.2139/ssrn.520382 
Curran, L., Escaith, H., Hallaert, J. J., \& Koopmann, G. (2009). The impact of the financial and economic crisis on world trade and trade policy. Intereconomics, 44(5), 264-293. https://doi.org/10.1007/s10272-009-0305-z

Davis, S. J. (2016). An index of global economic policy uncertainty (NBER Working Paper). National Bureau of Economic Research, Inc. https://doi.org/10.3386/w22740

Ding, Z., Liu, Z., Zhang, Y., \& Long, R. (2017). The contagion effect of international crude oil price fluctuations on Chinese stock market investor sentiment. Applied Energy, 187, 27-36. https://doi.org/10.1016/j.apenergy.2016.11.037

Fan, W., Fang, S., \& Lu, T. (2014). Macro-factors on gold pricing during the financial crisis. China Finance Review International, 4(1), 58-75. https://doi.org/10.1108/cfri-09-2012-0097

Fang, L., Chen, B., Yu, H., \& Qian, Y. (2018). The importance of global economic policy uncertainty in predicting gold futures market volatility: A GARCH-MIDAS approach. Journal of Futures Markets, 38(3), 413-422. https://doi.org/10.1002/fut.21897

Fic, T. M., \& Saqib, O. F. (2006). Political instability and the August 1998 Ruble crisis. Journal of Economic Integration, 21(4), 764-783. https://doi.org/10.11130/jei.2006.21.4.764

Ghosh, A. (2016). What drives gold demand in central bank's foreign exchange reserve portfolio. Finance Research Letters, 17, 146-150. https://doi.org/10.1016/j.frl.2016.03.007

Gokmenoglu, K. K., \& Fazlollahi, N. (2015). The interactions among gold, oil, and stock market: Evidence from S\&P500. Procedia Economics and Finance, 25, 478-488. https://doi.org/10.1016/s2212-5671(15)00760-1

Goldstein, M. (2011). The Asian financial crisis: origins, policy prescriptions and lessons. Journal of African Economies, 10(Suppl 1), 72-103. https://doi.org/10.1093/jae/10.suppl1.72

Goodnight, G. T., \& Green, S. (2010). Rhetoric, risk, and markets: The dot-com bubble. Quarterly Journal of Speech, 96(2), 115-140. https://doi.org/10.1080/00335631003796669

Griffithjones, S., Cailloux, J., \& Pfaffenzeller, S. (1998). The East Asian financial crisis: A reflection on its causes, consequences and policy implications (IDS Discussion Paper, 367). http://www.ids.ac.uk/files/DP367.pdf

Hansen, B. E. (1992). Tests for parameter instability in regressions with $\mathrm{I}(1)$ processes. Journal of Business and Economic Statistics, 20(1), 45-59. https://doi.org/10.1198/073500102753410381

Hodson, D., \& Mabbett, D. (2009). UK economic policy and the global financial crisis: Paradigm lost. Journal of Common Market Studies, 47(5), 1041-1061. https://doi.org/10.1111/j.1468-5965.2009.02034.x

Iqbal, J. (2017). Does gold hedge stock market, inflation and exchange rate risks? An econometric investigation. International Review of Economics and Finance, 48, 1-17. https://doi.org/10.1016/j.iref.2016.11.005

Ischuk, T. L., Zhilkin, D. V., \& Aikina, T. Y. (2016). Gold as a tool for hedging financial risks. IOP Conference Series: Earth and Environmental Science (Vol. 43, 1). https://doi.org/10.1088/1755-1315/43/1/012085

Jain, A., \& Biswal, P. C. (2016). Dynamic linkages among oil price, gold price, exchange rate, and stock market in India. Resources Policy, 49, 179-185. https://doi.org/10.1016/j.resourpol.2016.06.001

Jamal, B., Refk, S., \& Wohar, M. E. (2018). Measuring the response of gold prices to uncertainty: An analysis beyond the mean. Economic Modelling, 75, 105-116. https://doi.org/10.1016/j.econmod.2018.06.010

Jones, A. T., \& Sackley, W. H. (2016). An uncertain suggestion for gold-pricing models: The effect of economic policy uncertainty on gold prices. Journal of Economics and Finance, 40(2), 367-379. https://doi.org/10.1007/s12197-014-9313-3 
Joy, M. (2011). Gold and the U.S. dollar: Hedge or haven. Finance Research Letters, 8(3), 120-131. https://doi.org/10.1016/j.frl.2011.01.001

Jun, J. H. (2009). Global financial crisis and gold market. Social Science Electronic Publishing. https://doi.org/10.2139/ssrn.1397904

Junttila, J. P., Pesonen, J., \& Raatikainen, J. (2018). Commodity market based hedging against stock market risk in times of financial crisis: The case of crude oil and gold. Journal of International Financial Markets Institutions \& Money, 56, 255-280. https://doi.org/10.1016/j.intfin.2018.01.002

Kumar, D. (2014). Return and volatility transmission between gold and stock sectors: Application of portfolio management and hedging effectiveness. IIMB Management Review, 26(1), 5-16. https://doi.org/10.1016/j.iimb.2014.01.003

Leger, L. A., \& Leone, V. (2008). Changes in the risk structure of stock returns: Consumer confidence and the dot-com bubble. Review of Financial Economics, 17(3), 228-244. https://doi.org/10.1016/j.rfe.2007.08.001

Lian, Y. H., \& Zhang, L. (2013). Is there a ratchet effect in the gold price. South China Journal of Economics, 7, 64-77. http://en.cnki.com.cn/Article_en/CJFDTOTAL-NFJJ201307010.htm

Lin, J. Y., \& Treichel, V. (2012). The unexpected global financial crisis: Researching its root cause (Policy Research Working Paper). The World Bank. https://doi.org/10.1596/1813-9450-5937

Longstaff, F. A. (2010). The subprime credit crisis and contagion in financial markets. Journal of Financial Economics, 97(3), 436-450. https://doi.org/10.1016/j.jfineco.2010.01.002

Lutz, C. (2015). The impact of conventional and unconventional monetary policy on investor sentiment. Journal of Banking \& Finance, 61, 89-105. https://doi.org/10.1016/j.jbankfin.2015.08.019

Mills, T. (2004). Exploring the relationship between gold and the dollar. Significance, 1(3), 113-115. https://doi.org/10.1111/j.1740-9713.2004.00042.x

Mixon, S. (2006). Political and monetary uncertainty during the greenback era: Evidence from gold options. SSRN Electronic Journal. https://doi.org/10.2139/ssrn.933737

Neill, F. J. (1987). The inflation rate of the price of gold, expected prices and interest rates. Journal of Macroeconomics, 9(1), 71-82. https://doi.org/10.1016/s0164-0704(87)80007-1

Nyblom, J. (1989). Testing for the constancy of parameters over time. Journal of the American Statistical Association, 84(445), 223-230. https://doi.org/10.2307/2289867

Pastor, L., \& Veronesi, P. (2012). Uncertainty about government policy and stock prices. Journal of Finance, 67(4), 1219-1264. https://doi.org/10.3386/w16128

Pesaran, M. H., \& Timmermann, A. (2005). Small sample properties of forecasts from autoregressive models under structural breaks. Journal of Econometrics, 129(1-2), 183-217. https://doi.org/10.1016/j.jeconom.2004.09.007

Piffer, M., \& Podstawski, M. (2016). Identifying uncertainty shocks using the price of gold. The Economic Journal, 128, 3266-3284. https://doi.org/10.2139/ssrn.2737262

Pukthuanthong, K., \& Roll, R. (2011). Gold and the dollar (and the euro, pound, and yen). Journal of Banking and Finance, 35(8), 2070-2083. https://doi.org/10.1016/j.jbankfin.2011.01.014

Qadan, M., \& Yagil, J. (2012). Fear sentiments and gold price: Testing causality in-mean and in-variance. Applied Economics Letters, 19(4), 363-366. https://doi.org/10.1080/13504851.2011.579053

Raza, S. A., Shah, N., \& Shahbaz, M. (2018). Does economic policy uncertainty influence gold prices? Evidence from a nonparametric causality-in-quantiles approach. Resources Policy, 57, 61-68. https://doi.org/10.1016/j.resourpol.2018.01.007

Reboredo, J. C. (2013). Is gold a hedge or safe haven against oil price movements. Resources Policy, 38(2), 130-137. https://doi.org/10.1016/j.resourpol.2013.02.003 
Shahzad, S. J. H., Mensi, W., Hammoudeh, S., Sohail, A., \& Al-Yahyaee, K. H. (2019). Does gold act as a hedge against different nuances of inflation? Evidence from Quantile-on-Quantile and causalityin-quantiles approaches. Resources Policy, 62, 602-615.

https://doi.org/10.1016/j.resourpol.2018.11.008

Shukur, G., \& Mantalos, P. (1997). Size and power of the RESET test as applied to systems of equations: A bootstrap approach (Working Paper). Department of Statistics, University of Lund.

Shukur, G., \& Mantalos, P. (2000). A simple investigation of the granger-causality test in integratedcointegrated VAR systems. Journal of Applied Statistics, 27(8), 1021-1031. https://doi.org/10.1080/02664760050173346

Stockhammer, E., \& Grafl, L. (2010). Financial uncertainty and business investment. Review of Political Economy, 22(4), 551-568. https://doi.org/10.1080/09538259.2010.510317

Su, C. W., Li, Z. Z., Chang, H. L., \& Oana-Ramona, L. (2017). When will occur the crude oil bubbles? Energy Policy, 102, 1-12. https://doi.org/10.1016/j.enpol.2016.12.006

Su, C. W., Khan, K., Tao, R., \& Nicoleta-Claudia, M. (2019a). Does geopolitical risk strengthen or depress oil prices and financial liquidity? Evidence from Saudi Arabia. Energy, 187, 116003. https://doi.org/10.1016/j.energy.2019.116003

Su, C. W., Wang, X. Q., Tao, R., \& Oana-Ramona, L. (2019b). Do oil prices drive agricultural commodity prices? Further evidence in a global bio-energy context. Energy, 172, 691-701. https://doi.org/10.1016/j.energy.2019.02.028

Taylor, J. B. (2009). Economic policy and the financial crisis: An empirical analysis of what went wrong. Critical Review, 21(2-3), 341-364. https://doi.org/10.1080/08913810902974865

Thorarinsson, K., \& Eshraghi, A. (2013). The financial impact of fed policy statements and chairman sentiment: The case of gold and silver markets. SSRN Electronic Journal. https://doi.org/10.2139/ssrn.2278239

Wang, C. (2019). Is gold a hedge and safe haven for stock market. Applied Economics Letters, 26(13), 1080-1086. https://doi.org/10.1080/13504851.2018.1537469

Wang, K. M. (2013). Can gold effectively hedge risks of exchange rate. Journal of Business Economics and Management, 14(5), 833-851. https://doi.org/10.3846/16111699.2012.670133

Wang, Y. S., \& Chueh, Y. L. (2013). Dynamic transmission effects between the interest rate, the U.S. dollar, and gold and crude oil prices. Economic Modelling, 30, 792-798.

https://doi.org/10.1016/j.econmod.2012.09.052

Wen, Y. (2014). When and how to exit quantitative easing. Federal Reserve Bankorita of St. Louis Review, 96(3), 243-265. https://doi.org/10.20955/r.96.243-265

World Gold Council. (2020). https://www.gold.org/

Wu, S., Tong, M., Yang, Z. Y., \& Derbali, A. (2019). Does gold or Bitcoin hedge economic policy uncertainty. Finance Research Letters, 31, 171-178. https://doi.org/10.1016/j.frl.2019.04.001

Yi, J. H., \& Refalo, J. (2013). How is quantitative easing different from operation twist? A look at the announcement effect on broad stock index and gold price. Journal of International Finance \& Economics, 13(4), 71-76. https://doi.org/10.18374/JIFE-13-4.8

Yu, Y. D. (2008). China's economic growth, global economic crisis and China's policy responses. Pakistan Development Review, 47(4), 337-355. https://doi.org/10.4337/9780857931702.00017

Zhou, Y., Han, L., \& Yin, L. (2017). Is the relationship between gold and the U.S. dollar always negative? The role of macroeconomic uncertainty. Applied Economics, 50(31), 354-370. https://doi.org/10.1080/00036846.2017.1313956

Ziaei, S. M. (2012). Effects of gold price on equity, bond and domestic credit: Evidence from ASEAN +3. Procedia - Social and Behavioral Sciences, 40, 341-346. https://doi.org/10.1016/j.sbspro.2012.03.197 